\title{
Water Vapour Sorption and Moisture Transport in and Across Fibre Direction of Wood
}

\author{
Alexander Murr ( $\nabla$ alexander.murr@gmx.at) \\ Universität Innsbruck: Universitat Innsbruck https://orcid.org/0000-0003-3874-9220
}

\section{Research Article}

Keywords: Water vapour sorption, Sorption kinetics, Moisture transport, Diffusion, Water vapour transport, Wood

Posted Date: December 1st, 2021

DOI: https://doi.org/10.21203/rs.3.rs-1054651/v1

License: (9) This work is licensed under a Creative Commons Attribution 4.0 International License. Read Full License

Version of Record: A version of this preprint was published at Cellulose on March 30th, 2022. See the published version at https://doi.org/10.1007/s10570-022-04520-x. 


\section{Water vapour sorption and moisture transport in 2 and across fibre direction of wood}

\section{Alexander Murr}

4

5 Received: date / Accepted: date

6 Abstract Water vapour sorption experiments are frequently used to charac7 terise the absorption and desorption of water in wood during transient con8 ditions in relative humidity. When interpreting such experiments, it is still 9 unclear to what extend the resulting time-dependent change of sample mass 10 (i.e. sorption kinetics) is influenced by moisture transport, sorption and sorp11 tion related processes. To evaluate the impact of water vapour diffusion under 12 such transient conditions, this study investigates the sorption kinetics of small 13 wood samples with different lengths of transport pathways in and across fi14 bre direction. For this purpose, water vapour sorption experiments on Norway 15 spruce (Picea abies) samples were performed under identical climatic condi16 tions at ambient air pressure and ambient standard temperature. The results 17 showed that sample thickness has an impact on the sorption kinetics along 18 the whole tested range of relative humidity. Differences between the sorption 19 kinetics for samples in and across fibre direction were considerable at low rel20 ative humidity, indicating the relevance of water vapour diffusion through the 21 lumen-pit-ray system. In contrast at high relative humidity, differences between the sorption kinetics for samples in and across fibre direction started to disappear while the impact of sample thickness was still considerable. Therefore, it seems as if an additional or modified process that depends on the number of sorption sites becomes relevant at an increased moisture content of wood. This process, as well as the increasing uptake and release of water across fibre direction, should be further investigated to gain a better understanding of the absorption and desorption of water in wood.

29 Keywords Water vapour sorption - Sorption kinetics · Moisture transport ·

30 Diffusion · Water vapour transport · Wood

A. Murr

Unit of Material Technology, University of Innsbruck

Technikerstraße 13, 6020 Innsbruck, Austria

E-mail: alexander.murr@gmx.at

ORCID: 0000-0003-3874-9220 


\section{Introduction}

Wood is a hygroscopic material and capable to absorb large amounts of moisture from the surrounding air. Since many physical properties depend on the moisture content of wood (MC), a change of relative humidity $(\mathrm{RH})$ in the surrounding air causes a corresponding change in the physical properties of wood (Niemz 1993). To characterise the behaviour of wood and to identify the relevant processes during such non-stationary (i.e. transient) conditions, experimental investigations are often realised under transient conditions in RH (Christensen and Kelsey 1959; Christensen and Hergt 1969; Rosen 1978; Avramidis and Siau 1987; Wadsö 1994b; Hill et al. 2010; Eitelberger and Svensson 2012). According to the wide spread of dynamic vapour sorption devices, water vapour sorption experiments are frequently used for this purpose (Xie et al. 2011; Himmel and Mai 2015; Glass et al. 2017; Murr and Lackner 2018). Sample material is exposed to a well-defined change in $\mathrm{RH}$ and the resulting time-dependent change of sample mass (i.e. sorption kinetics ${ }^{1}$ ) is measured by weighting the sample. Consequently, this method provides direct information on the uptake and release of $\mathrm{H}_{2} \mathrm{O}$-molecules (hereinafter referred to as water). The interpretation of water vapour sorption experiments is though not trivial since moisture transport, sorption and sorption related processes are strongly coupled and might affect the measured sorption kinetics (Thybring et al. 2019). This raises the question of what kind of information can be extracted from the sorption kinetics of water vapour sorption experiments. Therefore, the processes that restrict the uptake and release of water in wood during a transient change of RH need to be identified. As water vapour has to be transported to and through the lumen-pit-ray system prior to getting bound on/in the cell wall and prior to any sorption related processes are initiated (e.g. release of binding energy, swelling, reorganisation of wood polymers), water vapour transport should be of particular importance for the initial sorption kinetics (see Fig. 1).

To avoid an overemphasis of water vapour diffusion through the lumen-pitray system, small or thin samples are often preferred in experimental investigations. Several studies have investigated the water vapour sorption behaviour of small wood samples but only a few analysed the impact of sample thickness or anatomical orientation on the measured sorption kinetics. Christensen and Kelsey (1959) compared the absorption kinetics between two $1 \mathrm{~mm}$ thick samples in longitudinal and tangential direction (i.e. in and across fibre direction) and a $40 \mu \mathrm{m}$ thick microtomed sample in tangential direction of Klinki pine (Araucaria hunsteinii) and found slightly faster sorption kinetics for the microtomed sample but no significant differences between the $1 \mathrm{~mm}$ samples. In contrast, Thybring et al. (2019) mentioned about a study on Mountain ash

1 There is a variety of expressions which are used synonymously for the time-dependent change of sample mass during water vapour sorption experiments in wood science: sorption kinetics, absorption/adsorption and desorption kinetics, kinetics, temporal mass change, sorption rates, absorption/adsorption and desorption rates, or rates. In this work the term sorption kinetics as well as absorption and desorption kinetics will be used. 


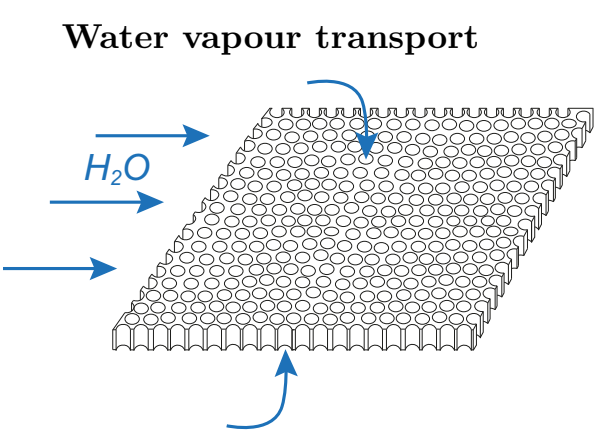

(a)

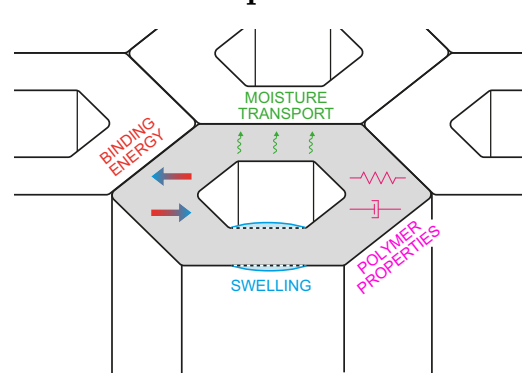

(b)

Fig. 1 Simplified illustration of the involved processes when wood is exposed to a change of relative humidity. Figure a indicates the transport of water vapour to the sample surface and through the lumen-pit-ray system. Figure b shows the concomitant processes in the cell wall of wood.

(Eucalyptus regnans) done by Christensen (1960), where the absorption kinetics between samples with a thickness between $20 \mu \mathrm{m}$ and $3 \mathrm{~mm}$ in tangential direction were considerable different at low $\mathrm{RH}$, while differences at high $\mathrm{RH}$ were not appreciable. However, Wadsö (1994b) compared the absorption kinetics of various soft- and hardwoods with a thickness between $3.8 \mathrm{~mm}$ and $22.8 \mathrm{~mm}$ (in longitudinal, tangential and radial direction) and found differences in the initial sorption kinetics at mid to high RH. Similarly, Nopens et al. (2019) have found differences in the absorption and desorption kinetics for samples with a thickness between $1 \mathrm{~mm}$ and $20 \mathrm{~mm}$ (in longitudinal direction) of Scots pine (Pinus sylvestris) and European beech (Fagus sylvatica). Further, a comparison of microtomed and cut Norway spruce wood (Picea abies) with a thickness of $25 \mu \mathrm{m}$ and $0.5 \mathrm{~mm}$ in longitudinal direction showed significant differences in the absorption kinetics at low RH (Murr and Lackner 2018). Similar to the different experimental observations, a variety of different approaches to model the moisture transport in wood can be found in the literature. Some authors have used a coupled transport model, where water vapour and bound water (i.e. water within the cell wall) were described by a separate diffusion equation (Krabbenhoft and Damkilde 2004; Frandsen et al. 2007; Eitelberger et al. 2011; Konopka and Kaliske 2018). Diffusion coefficients for water vapour were given to be (almost) constant while the diffusion coefficients for bound water were described by exponentially increasing functions with MC. A simplification of the coupled approach was given by Hozjan and Svensson (2011), where the bound water diffusion was shown by a theoretical analysis to be negligible, particularly at low RH (see also Eitelberger and Svensson 2012). On the contrary, other authors have neglected the transport of water vapour and instead used a diffusion equation for the transport of bound water combined with a certain boundary condition for the flux (Olek et al. 2011). Using an inverse analysis, a non-monotonic behaviour for the diffusion coefficients as well as differences in the diffusion coefficients between 
100 absorption and desorption were found with this model. In addition, a combined

101 transport approach has been used, where water vapour and bound water were

102 treated together with a single diffusion equation (Time 1998; Florisson et al.

103 2020). With this approach, an increase of diffusion coefficients with MC across

104 fibre direction was frequently reported, while diffusion coefficients in fibre di-

105 rection were given to decrease with MC (Droin-Josserand et al. 1989; Jakieła

106 et al. 2008; Kang et al. 2008). Consequently, there seems to be no consensus

107 on whether moisture transport - compared to sorption and sorption related

108 processes - can be neglected in water vapour sorption experiments on small

109 wood samples under ambient conditions.

110 The objective of this work is thus to examine the impact of water vapour 111 diffusion through the lumen-pit-ray system on the uptake and release of water 112 during a transient change of $\mathrm{RH}$. Therefore, water vapour sorption experiments 113 are performed on thin Norway spruce plates with a different thickness along 114 the three main anatomical orientations (i.e. longitudinal, tangential, and ra115 dial). Experiments are carried out at ambient pressure and standard ambient 116 temperature along a wide range of $\mathrm{RH}$. The sorption kinetics between sam117 ples in fibre direction (longitudinal) and across fibre direction (tangential and 118 radial) are compared during absorption and desorption to identify the impact 119 of water vapour diffusion through the lumen-pit-ray system and to estimate 120 moisture dependent changes on the transport properties. With this informa121 tion the relevance of cell wall processes on the measured sorption kinetics 122 should be estimated. However, for quantitative statements on the impact of 123 cell wall processes on the uptake and release of water, different measurements 124 would be necessary. The presented experimental results can be used as a state125 of-the-art data for future modelling approaches and for a validation of existing transport concepts.

\section{Materials and methods}

128 2.1 Dynamic vapour sorption

129 All water vapour sorption experiments were carried out with the dynamic 130 vapour sorption device SPSx-1 $\mu$ (ProUmid GmbH, Germany). The device con131 sists of a climatic chamber, where up to 11 samples can be tested under iden132 tical pressure, temperature and RH conditions. Sample material is placed in 133 aluminium bowls on a rotating plate and the mass of the samples is measured 134 automatically by placing each sample bowl successively on a micro scale with a 135 reproducibility of $\pm 10 \mu \mathrm{g}$. Sample weighting is repeated at an 8 min interval to 136 ensure stabilised conditions inside the climatic chamber. At the beginning and 137 at the end of a weighting cycle (i.e. prior to the first and after the last sample 138 was weighted), an empty reference bowl is weighted to correct the adsorption 139 and desorption of water on the sample bowls and to correct a possible scale 140 drift (assuming a linear drift). Relative humidity is regulated by a moisten141 ing unit using dry air $(0.2 \% \mathrm{RH}$; hereinafter referred to as $0 \% \mathrm{RH})$ or water 
vapour-saturated air and the two fans create a circulating flow of the water vapour-air mixture inside the climatic chamber. $\mathrm{RH}$ can be changed stepwise by choosing the required step-sizes for absorption or desorption. Deviations to the pre-set $\mathrm{RH}$ can be ensured to be below $\pm 0.5 \% \mathrm{RH}$, except for $\mathrm{RH} \geq 80 \%$ $( \pm 1 \% \mathrm{RH})$. The integrated Peltier element ensures a constant temperature of $25{ }^{\circ} \mathrm{C}$ with a deviation below $\pm 0.1{ }^{\circ} \mathrm{C}$. More details on the dynamic sorption device can be found in Murr (2019).

\subsection{Sample preparation}

Samples were taken from the lower stem of a Norway spruce (Picea abies) grown in the West of Austria. A plank with a length of $1.5 \mathrm{~m}$ in longitudinal direction was cut through the centre of the stem and 136 annual rings were counted. After an initial drying phase of 7 days at ambient air, the plank was stored for 12 months in an air-conditioned room at a temperature of $21^{\circ} \mathrm{C}\left( \pm 3^{\circ} \mathrm{C}\right)$ and a relative humidity of $30 \%( \pm 10 \%)$. Prior to manipulation, the plank was cut to remove the inner and outer part (approximately 15 annual rings in each case). Thin samples were cut with a circular saw using a sharp blade with alternative top bevel teeth and a positive rake angle to minimise heat production. To compare the influence of sample thickness on the sorption kinetics, several samples with a thickness between $0.5 \mathrm{~mm}$ and $3 \mathrm{~mm}$ along the three anatomical orientations were cut (see Fig. 2).

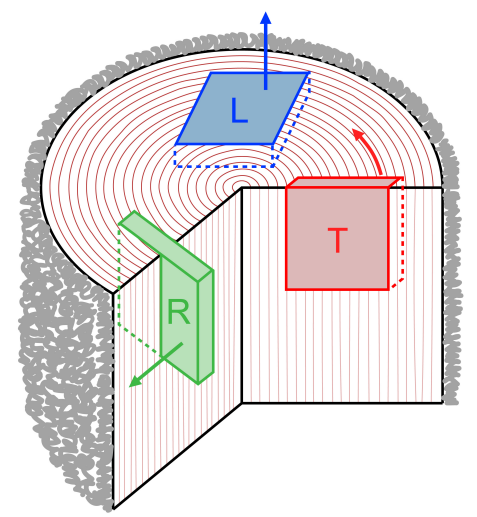

Fig. 2 Anatomical orientations of wood indicated with the three arrows for the longitudinal $(\mathrm{L})$, tangential $(\mathrm{T})$, and radial direction $(\mathrm{R})$. Samples were labelled corresponding to the direction of the surface normal of the thinnest dimension

Cross section was chosen to be large enough to minimise the impact of water vapour diffusion through the side surfaces (i.e. orthogonal to the sample thickness), but not too large to unnecessary slow down the time span for changing RH in the climatic chamber (Murr 2019). All samples were without any visible defects or growth irregularities and the density was determined 
Table 1 Sample dimensions at $\mathrm{MC} \approx 6 \%$ and minimum sample mass after precondition phase $\left(m_{0}\right)$ of used samples in the longitudinal $(\mathrm{L})$, tangential $(\mathrm{T})$ and radial $(\mathrm{R})$ direction

\begin{tabular}{lll}
\hline Dimensions $(\mathrm{mm} \times \mathrm{mm} \times \mathrm{mm})$ & Mass $(\mathrm{mg})$ & Label \\
\hline $0.5(\mathrm{~L}) \times 21.4(\mathrm{R}) \times 40.0(\mathrm{~T})$ & 157 & L_0.5mm \\
$1.0(\mathrm{~L}) \times 20.2(\mathrm{R}) \times 41.6(\mathrm{~T})$ & 299 & L_1mm \\
$2.0(\mathrm{~L}) \times 21.0(\mathrm{R}) \times 43.0(\mathrm{~T})$ & 607 & L_2mm \\
$3.0(\mathrm{~L}) \times 20.7(\mathrm{R}) \times 43.0(\mathrm{~T})$ & 888 & L_3mm \\
\hline $0.5(\mathrm{~T}) \times 21.2(\mathrm{R}) \times 43.6(\mathrm{~L})$ & 175 & T_0.5mm \\
$1.0(\mathrm{~T}) \times 21.2(\mathrm{R}) \times 43.6(\mathrm{~L})$ & 312 & T_1mm \\
$2.0(\mathrm{~T}) \times 22.2(\mathrm{R}) \times 43.6(\mathrm{~L})$ & 613 & T_2mm \\
$3.0(\mathrm{~T}) \times 21.6(\mathrm{R}) \times 43.6(\mathrm{~L})$ & 928 & T_3mm \\
\hline $0.5(\mathrm{R}) \times 21.5(\mathrm{~T}) \times 43.6(\mathrm{~L})$ & 173 & R_0.5mm \\
$1.0(\mathrm{R}) \times 21.6(\mathrm{~T}) \times 43.6(\mathrm{~L})$ & 361 & R_1mm \\
$2.0(\mathrm{R}) \times 22.1(\mathrm{~T}) \times 43.6(\mathrm{~L})$ & 605 & R_2mm \\
\hline
\end{tabular}

167

to be $370 \pm 40 \mathrm{~kg} \mathrm{~m}^{-3}$. To measure the uptake and release of water for the various samples under identical climatic conditions, one representative slice for each thickness and anatomical orientation was chosen (see Table 1). The restriction of the investigation to one sample each was possible as pre-testings have shown identical sorption kinetics between a number of samples for each thickness and orientation, including the samples which were investigated in this study. Further, it has to be mentioned that a complete run of the measurement as described in Section 2.3 takes more than 6 weeks. A successive measurement of, for example, 5 samples for each thickness and orientation would therefore extend the measurement to over half a year. The sample with a thickness of $3 \mathrm{~mm}$ in the radial direction was omitted in this work, as the maximum number of samples to be tested at once (i.e. under identical climatic conditions) was limited to 11 samples.

\subsection{Experimental set-up}

Samples according to Table 1 were distributed with decreasing thickness across the 11 sample bowls, starting with the thickest $(3 \mathrm{~mm})$ and ending with the thinnest samples $(0.5 \mathrm{~mm})$. The order of anatomical orientation (i.e. the direction of the thinnest sample dimension) was chosen for each thickness to be longitudinal, tangential and radial. Particular attention was given to maximise the accessibility of water vapour to the sample surface and to emphasise possible differences in the initial sorption kinetics of the various samples. This was done by mounting the thin wooden sample plates on a wire frame outside the sample bowl and parallel to the water vapour-air stream. Hence, samples were exposed directly in the circulating water vapour-air stream which avoids the paths of stagnant air when samples are placed inside a sample bowl (Murr 2019). An additional wire frame was placed on the reference bowl to correct for the adsorption and desorption of water on the wire frame of the 
194 samples. Samples were conditioned inside the climatic chamber at $\mathrm{T}=25^{\circ} \mathrm{C}$

195 and $0 \% \mathrm{RH}$ until equilibrium condition (EC) was reached (Eq. 1). After an

196 additional drying phase of $24 \mathrm{~h}$, samples were weighted to determine the min-

197 imum sample mass $m_{0}$ (see Table 1 ). To measure the sorption kinetics of the

198 various samples, $\mathrm{RH}$ was changed stepwise and kept constant until all samples

199 fulfilled the EC, defined as

$$
\frac{\mathrm{d}}{\mathrm{d} t}\left(\frac{m(t)}{m_{0}}\right)<0.00017 \% \mathrm{~min}^{-1}
$$

201 evaluated in a period of $120 \mathrm{~min}$. Here, $m(t)$ denotes the total sample mass and 202 a linear regression was used for the calculation. This mass stability criterion is 203 more than one order of magnitude lower than the most common used criterion 204 given in Glass et al. (2017). It should be noted that the sample with the slowest 205 sorption kinetic determined the EC and hence the time, when the next step 206 change in $\mathrm{RH}$ was initiated. Samples with a faster sorption kinetic had thus 207 an even lower EC than mentioned in Eq. 1, which might had an impact on the 208 sorption kinetic in the following step change of $\mathrm{RH}$ (Christensen and Hergt 209 1969). Step-size in $\mathrm{RH}$ was chosen to $\Delta \mathrm{RH}=10 \%$ between $0 \%$ and $90 \% \mathrm{RH}$ 210 at a constant temperature of $25^{\circ} \mathrm{C}$ (i.e. at standard ambient temperature). An 211 additional step to reach $94 \% \mathrm{RH}$ was used to provide a different starting MC 212 for desorption at $90 \%$ RH. After absorption was completed, a reverse order 213 sequence of the same step-sizes in $\mathrm{RH}$ was used for desorption. A change of $\mathbf{2 1 4}$ relative humidity inside the climatic chamber took between 1 and 2 min for the 215 given experimental set-up. Only for absorption above $70 \% \mathrm{RH}$ and desorption 216 below $20 \%$ RH, step changes in relative humidity needed more time until the $\mathbf{2 1 7}$ pre-set RH value was attained (see Fig. S5 in the Supplementary Information).

218 Weighting of the samples started approximately 5 min after a step change in 219 RH was initiated and was then repeated in an 8 min cycle until EC was reached. 220 As mentioned by Popescu and Hill (2013), a complete run in absorption and 221 desorption was performed in advance to reduce a possible impact of previous $\mathbf{2 2 2}$ sorption history on the sorption kinetics.

\subsection{Simulations}

224 To simulate the diffusion of water vapour through the lumen-pit-ray struc225 ture of wood, some simplified assumption were made. The wood samples were treated as a homogeneous sheet with a thickness corresponding to Table 1. Uptake and release of water on/in the cell wall as well as the transport of moisture through the cell wall were assumed to be very fast (i.e. instantaneous). Further, processes within the cell wall and their impact on the diffusion of water vapour were not considered (e.g. a possible reduction of water vapour diffusion due to a local drop of RH caused by the release of binding energy during absorption of water on/in the cell wall). Using these simplifications and assuming a one-dimensional moisture transport through the sample, the diffusion of water 
vapour in wood can be written approximately as (see e.g. Murr 2019)

$$
\frac{\partial \rho_{w v}}{\partial t}=D_{\mathrm{eff}} \cdot \frac{\partial^{2} \rho_{w v}}{\partial x^{2}}
$$

Here, $\rho_{w v}=\rho_{w v}(x, t)$ is the concentration of water vapour in $\mathrm{kg} \mathrm{m}^{-3}$ and the effective diffusion coefficient for water vapour through wood includes the absorption and desorption of water, $D_{\text {eff }}=\frac{\xi \cdot D_{a}}{1+\Delta R}$ in $\mathrm{m}^{2} \mathrm{~s}^{-1} \cdot D_{a}$ is the water vapour diffusion coefficient in air and $\xi$ is a constant reduction factor for the hindered transport through the lumen-pit-ray structure. The uptake and release of water on/in the cell wall considerably reduces the diffusion of water vapour through the samples and is given by the sink factor $\Delta R$. This factor can be calculated by the change in bound water concentration divided by the change of water vapour concentration for each step change in RH. It should be mentioned that $\Delta R$ was assumed to be constant during each step change in RH. Using Eq. 2 and an instantaneous change of water vapour on the surface of the sample, the standardised change of sample mass (Eq. 4) during a step change in RH can be evaluated as (Crank 1975)

$$
\frac{\Delta m(t)}{\Delta m_{\max }}=1-\sum_{n=0}^{\infty} \frac{8}{\pi^{2}(2 n+1)^{2}} \cdot \exp \left(-\frac{D_{\mathrm{eff}} \cdot t \cdot \pi^{2}(2 n+1)^{2}}{d^{2}}\right)
$$

where $d$ is the thickness of the sample. To evaluate Eq. 2 under more realistic boundary conditions (i.e. the measured $\mathrm{RH}$ inside the measuring chamber given in Fig. S5), a simulation based on the interpolated $\mathrm{RH}$ values was carried out (Fig. 6b and Fig. 8). For the simulations the software Wolfram Mathematica 12.1 was used. The reduction factor in longitudinal direction was chosen as $\xi=0.9$ (Frandsen et al. 2007) and the water vapour diffusion coefficient in air was used as mentioned in Schirmer (1938). This results in an effective water vapour diffusion coefficient of $D_{\text {eff }} \approx 5 \cdot 10^{-9} \mathrm{~m}^{2} \mathrm{~s}^{-1}$ for the step change $0 \% \rightarrow 10 \%$ RH (see Fig. 6).

\subsection{Error estimation}

Regarding the measurement error, the humidification process inside the climatic chamber (Murr 2019) and the variation in sample material (i.e. sample geometry and density) were identified as the main sources of error in the given experimental set-up. On the basis of pre-testings with cut samples of the same wooden plank, these errors were estimated to be below $3 \%$ of the total mass change per step.

\section{Results and discussion}

To compare the sorption kinetics between samples with a different sample thickness or among different step changes in RH, the time-dependent change 
$\mathbf{2 6 9}$ of sample mass was either standardised to minimum sample mass $\left(m_{0}\right)$ or to $\mathbf{2 7 0}$ the total mass change of the investigated step change in $\mathrm{RH}$,

$$
\frac{\Delta m(t)}{\Delta m_{\max }}=\frac{m(t)-m(0)}{m\left(t_{\max }\right)-m(0)}
$$

which is sometimes termed as fractional mass change $E(t)$. For each step change the time was set to start at $t=0$ and $t_{\max }$ refers to the time, when EC (Eq. 1) was fulfilled by the sample with the slowest sorption kinetics $\left(t_{\max }>1000 \mathrm{~min}\right)$. To evaluate the sample mass at a specific time, a linear interpolation of the measured data was use. Moisture content of wood is generally a time-dependent function and was calculated on the basis of minimum sample mass, $M C(t)=\left(m(t)-m_{0}\right) / m_{0}$. In the following, desorption data were given in terms of absolute values, except for Fig. 3b, Fig. $4 \mathrm{~b}$ and Fig. S1b in the Supplementary Information. The time axis was chosen to emphasise the initial sorption kinetics in the figures and is always considerably smaller than the time when EC was reached. Experimental results of the step change $90 \%$ $\rightarrow 94 \% \mathrm{RH}$ and $94 \% \rightarrow 90 \% \mathrm{RH}$ were only shown in Fig. 9 and Fig. S4 in the Supplementary Information. This was done to avoid confusion, since differences in step-size have an impact on both sorption kinetics and total mass change per step (Christensen and Kelsey 1959; Murr 2019).

\subsection{Samples with different thickness}

\section{In fibre direction:}

The absorption and desorption kinetics for samples with a thickness between $0.5 \mathrm{~mm}$ and $3 \mathrm{~mm}$ in longitudinal direction (i.e. in fibre direction) is shown for an exemplary step change in Fig. 3a,b. In both cases, differences in the sorption kinetics among the various samples can be seen particularly at the initial phase $(\mathrm{t} \lesssim 30 \mathrm{~min})$ of the mass change. With increasing time, these differences in the sorption kinetics decrease leading to a similar increase or decrease of standardised sample mass until EC was reached (indicated by the straight dotted line). To investigate if the impact of sample thickness on the initial sorption kinetics is also present for other step changes in $\mathrm{RH}$, a representation of the uptake and release of water after an arbitrary chosen evaluation time of $t_{e v}=10$ min was used. For each step change in RH, differences in the amount of absorbed (Fig. 3c) and desorbed water (Fig. 3d) can be seen among the four tested samples. A minimum in the differences was observed in the mid range of $\mathrm{RH}$, which corresponds to the smallest total mass change per step (see bars in the background of Fig. 3c,d). As the standardised mass change of the thinner samples is always faster than for the thicker ones, these results show that sample thickness has a significant impact on the initial sorption kinetics even for samples with a thickness of $1 \mathrm{~mm}$ and below. To investigate the impact of sample thickness on the sorption kinetics at a later phase, uptake and release of water was evaluated at $t_{e v}=100 \mathrm{~min}$. In contrast to the initial 


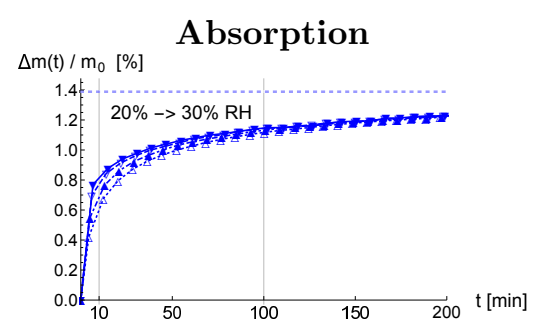

(a)

$t_{e v}=10 \mathrm{~min}$

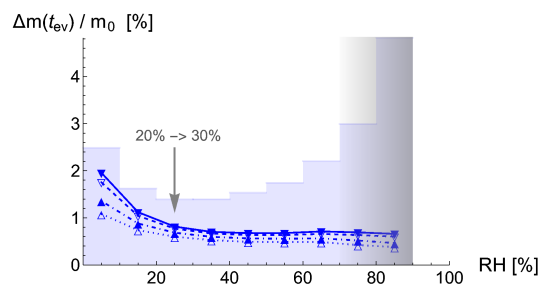

(c)

$$
t_{e v}=100 \mathrm{~min}
$$

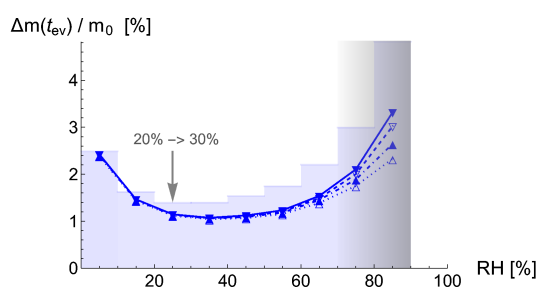

(e)

\section{Desorption}

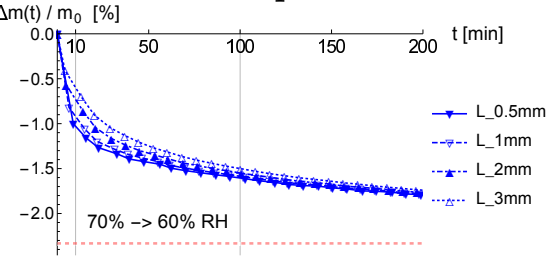

(b)

$$
t_{e v}=10 \mathrm{~min}
$$

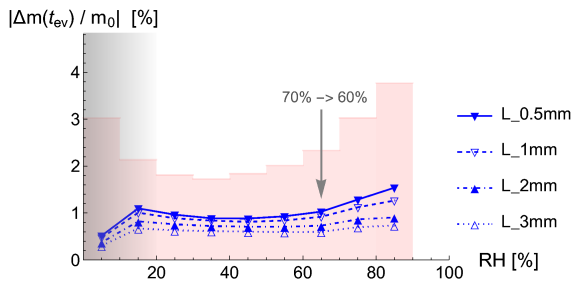

(d)

$t_{e v}=100 \mathrm{~min}$

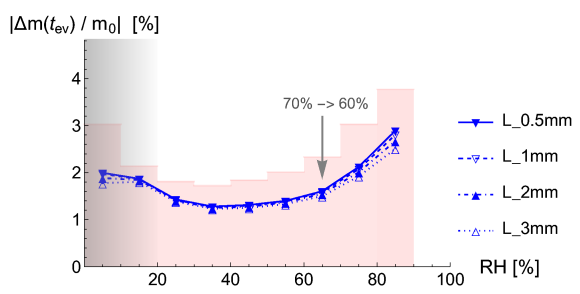

(f)

Fig. 3 Comparison of the absorption (left) and desorption behaviour (right) between longitudinal samples with different thickness. First row shows the sorption kinetics for a selected step change in absorption (a) and desorption (b). Middle row shows the uptake (c) and release of water (d) after $10 \mathrm{~min}$ for each step change in $\mathrm{RH}$ and the last row shows the uptake (e) and release of water (f) after $100 \mathrm{~min}$. Markers were placed in the middle of each step change in $\mathrm{RH}$ and bars in the background show the total mass change when EC was fulfilled. The grey area indicates the range with a slow change of $\mathrm{RH}$ inside the measuring chamber. Error bars were omitted for a better comparability and the interpolated lines between the measured data are for illustration purposes only 
310 phase, differences among the samples almost disappeared in the low and mid 311 range of $\mathrm{RH}$ for both absorption (Fig. 3e) and desorption (Fig. 3f). Since equi312 librium mass was not reached at this time (see differences between markers 313 and bars in the background of Fig. 3e,f), the remaining mass change must $\mathbf{3 1 4}$ be almost independent of water vapour diffusion through the lumen-pit-ray 315 system. Hence, it seems as if processes within the cell wall are dominating the 316 sorption kinetics of longitudinal samples in this phase. An exception is though $\mathbf{3 1 7}$ the high range of $\mathrm{RH}$, where significant differences in the uptake and release 318 of water among the samples can be seen even after $100 \mathrm{~min}$. The impact of 319 sample thickness for samples in fibre direction lasts thus much longer in the 320 high range of $\mathrm{RH}$ compared to the mid and low range of $\mathrm{RH}$. For the step 321 change $10 \% \rightarrow 0 \% \mathrm{RH}$, differences among the samples were also detected after $322100 \mathrm{~min}$ (Fig. 3f). These differences seem though to be an effect of the slow 323 change of RH inside the measuring chamber of the used sorption device (see 324 Section 2.3 and Fig. S5), which slows down the release of water at low RH as well as the uptake of water at high RH (see grey area in Fig. 3c-f).

\section{Across fibre direction:}

An evaluation of the absorption and desorption kinetics for samples with a thickness between $0.5 \mathrm{~mm}$ and $3 \mathrm{~mm}$ in tangential direction (i.e. across fibre direction) during an exemplary step change in $\mathrm{RH}$ is given in Fig. 4a,b. Differences in the sorption kinetics among the various samples can be clearly seen and the uptake and release of water is noticeable slower than for the longitudinal samples. An evaluation of the initial sorption kinetics $\left(t_{e v}=10 \mathrm{~min}\right)$ over the whole tested range of $\mathrm{RH}$ shows a significant impact of sample thickness on the uptake (Fig. 4c) and release of water (Fig. 4d). Hence, for tangential samples with a thickness of $3 \mathrm{~mm}$ and below, an even larger impact of sample thickness on the initial sorption kinetics was observed. Similar results were obtained by comparing the radial samples as shown in Fig. S1 in the Supplementary Information. This is contrary to the findings of Christensen (1960) reported in Thybring et al. (2019), where no differences in the sorption kinetics of tangential samples (with a thickness between $20 \mu \mathrm{m}$ and $3 \mathrm{~mm}$ ) were reported above $60 \% \mathrm{RH}$. An investigation of the uptake (Fig. 4e) and release of water (Fig. 4f) at an evaluation time of 100 min shows further, that these differences among the tangential samples generally last longer than for the longitudinal samples. Water vapour diffusion through the lumen-pit-ray system seems thus to be more dominant (i.e. slower) across fibre direction than in fibre direction. Consequently, for investigations of sorption and sorption related processes, thin longitudinal samples are more recommended than thin tangential or radial samples as water vapour diffusion has less impact on the uptake and release of water. A fact that remains unclear is the proximity of the uptake and release of water between the $1 \mathrm{~mm}$ and $2 \mathrm{~mm}$ tangential samples in the low range of $\mathrm{RH}$ (Fig. 4). An explanation based on an additional transport path for water vapour through the not sealed side surface of the tangential samples seems to be improbably, as the large differences between the sorption kinet- 


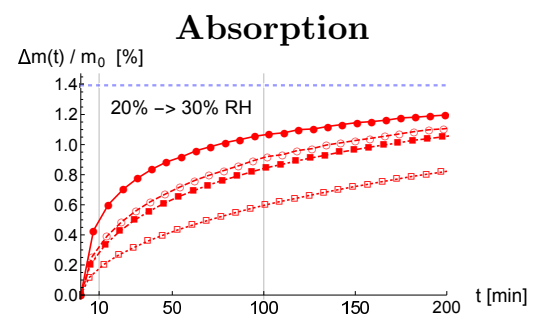

(a)

$t_{e v}=10 \mathrm{~min}$

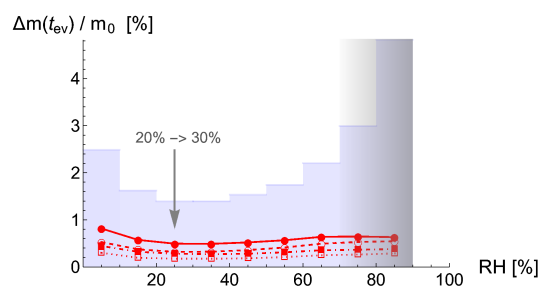

(c)

$$
t_{e v}=100 \mathrm{~min}
$$

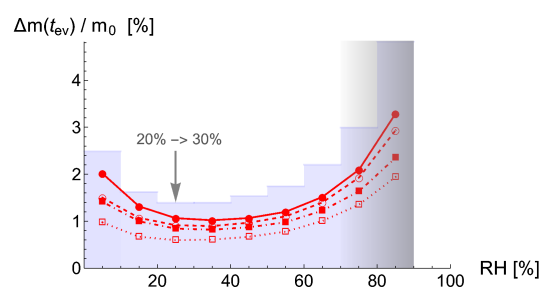

(e)

\section{Desorption}

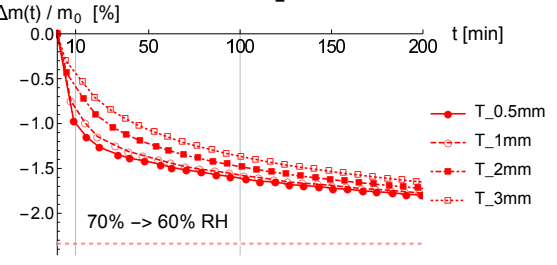

(b)

$$
t_{e v}=10 \mathrm{~min}
$$

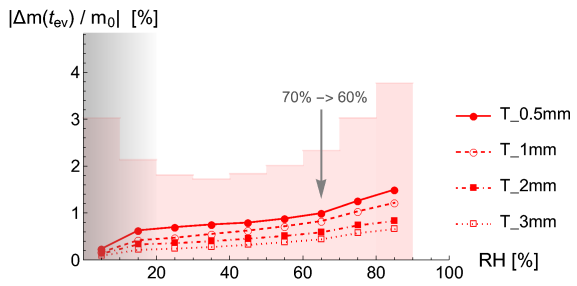

(d)

$t_{e v}=100 \mathrm{~min}$

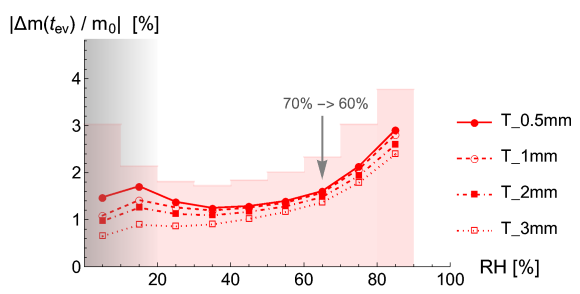

(f)

Fig. 4 Comparison of the absorption (left) and desorption behaviour (right) between tangential samples with different thickness. First row shows the sorption kinetics for a selected step change in absorption (a) and desorption (b). Middle row shows the uptake (d) and release of water (d) after $10 \mathrm{~min}$ for each step change in $\mathrm{RH}$ and the last row shows the uptake (e) and release of water (f) after $100 \mathrm{~min}$. Markers were placed in the middle of each step change in $\mathrm{RH}$ and bars in the background show the total mass change when EC was fulfilled. The grey area indicates the range with a slow change of $\mathrm{RH}$ inside the measuring chamber. Error bars were omitted for a better comparability and the interpolated lines between the measured data are for illustration purposes only 
ics of the $2 \mathrm{~mm}$ and $3 \mathrm{~mm}$ samples do not support this possibility. The radial samples showed a similar effect, although the proximity of the $1 \mathrm{~mm}$ and $2 \mathrm{~mm}$ sample was less pronounced (see Fig. S1 in the Supplementary Information).

\subsection{Samples with different anatomical orientation}

Low range of $R H$ :

Investigating the differences between the sorption kinetics of samples in and across fibre direction at low RH, longitudinal samples show a considerable faster absorption (Fig. 5a) and desorption kinetics (Fig. 5b) than the tangential samples.

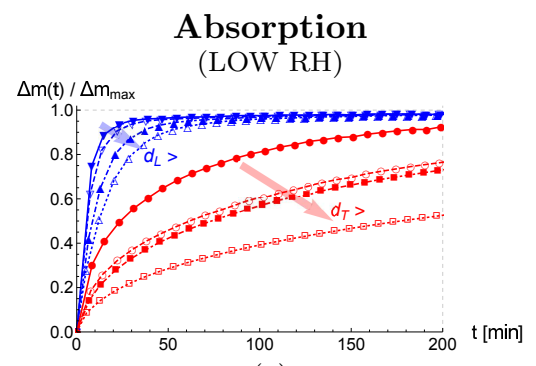

(a)

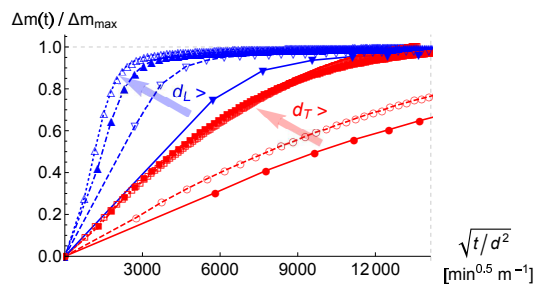

(c)

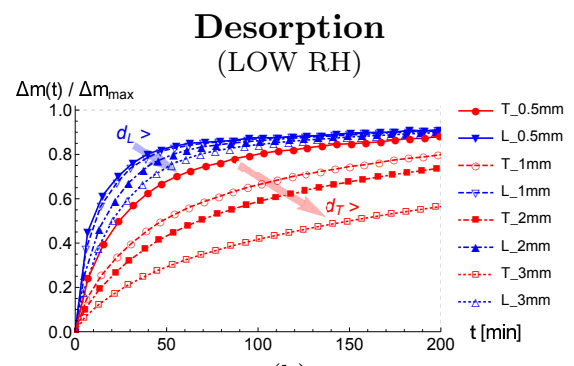

(b)

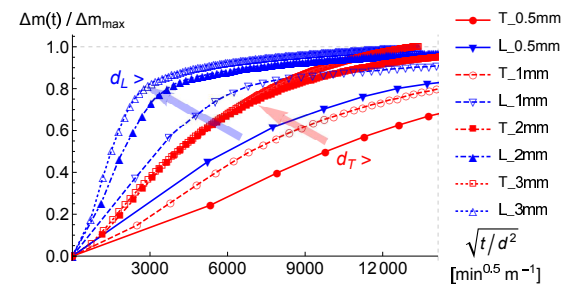

(d)

Fig. 5 Comparison of the sorption kinetics between samples with a different thickness in the longitudinal (blue) and tangential (red) direction in the low range of $\mathrm{RH}$. Absorption kinetics $(0 \% \rightarrow 10 \% \mathrm{RH})$ are shown left $(\mathrm{a}, \mathrm{c})$ and desorption kinetics $(20 \% \rightarrow 10 \% \mathrm{RH})$ right $(\mathrm{b}, \mathrm{d})$. Error bars were omitted for a better comparability and the interpolated lines are for illustration purposes only

For both orientations, thicker samples show a slower standardised mass change than the thinner samples, which is indicated by the arrows for each anatomical orientation. Similar results were obtained with the radial samples as shown in 368 Fig. S2 in the Supplementary Information. To evaluate if diffusion of water 369 vapour through the lumen-pit-ray system has a significant contribution on the sorption kinetics, an illustration over $\sqrt{t / d^{2}}$ was used. For a sheet diffusion process with an instantaneous change of $\mathrm{RH}$ at the surface of the sheet (Eq. 3), this illustration leads to an identical mass change for each thickness (Fig. 6a) 


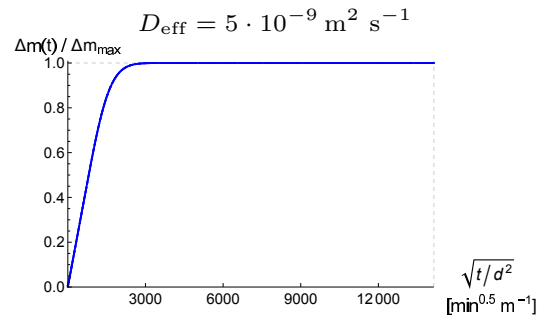

(a)

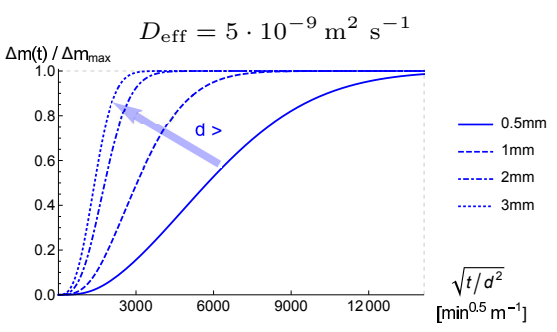

(b)

Fig. 6 Solutions for diffusion in a plane sheet with different thickness to simulate the water vapour diffusion in the longitudinal direction. Instantaneous (a) and the measured change

of $\mathrm{RH}$ inside the measuring chamber (b) were used as boundary conditions at the surface

(see also Crank 1975). However, if the measured change of RH in the measuring chamber is used as a boundary condition at the sample surface (see Fig. S5a in the Supplementary Information), differences in the mass change become apparent (Fig. 6b). Analysing the measured sorption kinetics in the $\sqrt{t / d^{2}}$ representation, differences among the samples with different thickness can be seen for both orientations (Fig. 5c,d). The thinner samples seem to be delayed in their sorption kinetics while with increasing thickness samples tend towards identical kinetics. Comparing the measured mass change of the longitudinal ples with the simulated solution for the sheet diffusion process, a certain (1) cell wall have a smaller impact on the sorption kinetics in this range of $\mathrm{RH}$.

\section{High range of $R H$ :}

In the high range of $\mathrm{RH}$, the sorption kinetics of samples in longitudinal and tangential direction show a remarkable similarity during absorption (Fig. 7a) and particularly during desorption (Fig. 7b). For absorption, an identical uptake of water can be observed for the $0.5 \mathrm{~mm}$ samples while with increasing thickness the differences between the longitudinal and tangential samples increase. In contrast for desorption, the release of water is identical for the $0.5 \mathrm{~mm}$ samples as well as for the $1 \mathrm{~mm}$ samples and only slight differences were found for the thicker samples. A similar trend was observed between the longitudinal and radial samples (Fig. S3 in the Supplementary Information). Therefore, the sorption kinetics between samples in and across fibre direction seems to be more similar for desorption, but this appears to be related to the moisture content of the wood samples (see Section Transition low to high range of $\mathrm{RH}$ ). A fact that was not expected is the difference in the sorption kinetics among samples with a different thickness. Even though the anatomical orientation is less relevant for the uptake and release of water at high $\mathrm{RH}$, 


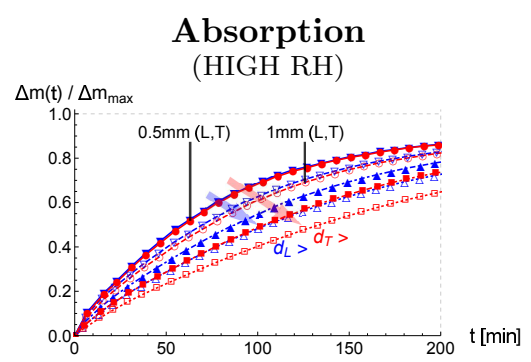

(a)

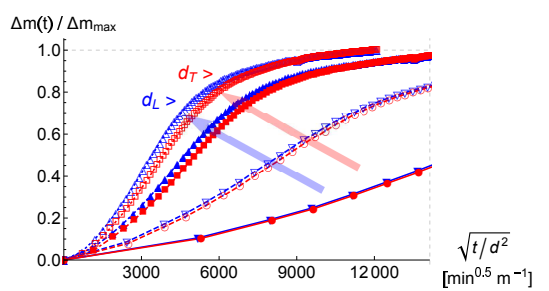

(c)

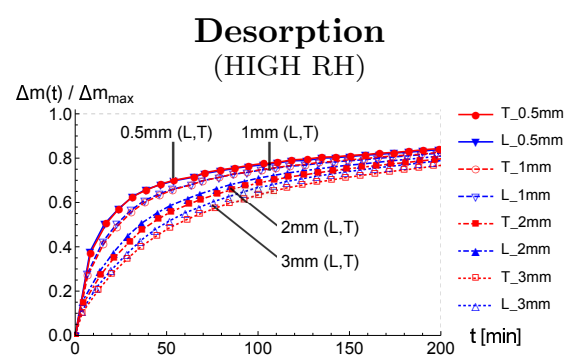

(b)

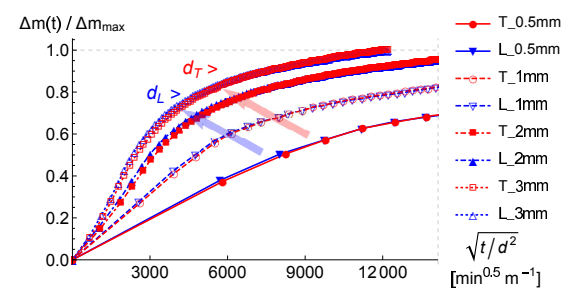

(d)

Fig. 7 Comparison of the sorption kinetics between samples with a different thickness in the longitudinal (blue) and tangential (red) direction in the high range of $\mathrm{RH}$. Absorption kinetics $(80 \% \rightarrow 90 \% \mathrm{RH})$ are shown left $(\mathrm{a}, \mathrm{c})$ and desorption kinetics $(90 \% \rightarrow 80 \% \mathrm{RH})$ right $(b, d)$. Error bars were omitted for a better comparability and the interpolated lines are for illustration purposes only

sample thickness still has a considerable impact. Pre-testings on another sample set of the same wooden plank with the same step changes in RH confirmed this results. Furthermore, experiments with a step-size in relative humidity of $\Delta \mathrm{RH}=30 \%$ led to similar results. To evaluate if a diffusion process through the sample thickness can explain these differences, a representation of the sorption kinetics over $\sqrt{t / d^{2}}$ was used. As shown in Fig. 7c and Fig. 7d, both the shape of the sorption kinetics as well as the differences among the samples deviate considerably from the simulated water vapour diffusion behaviour given in Fig. 6b. This deviation also becomes evident when comparing the measured desorption kinetics (Fig. 7b) with a corresponding simulated solution for a plane sheet diffusion process using an arbitrary chosen high and a low diffusion coefficient. With a high diffusion coefficient, differences between the four samples occur mainly in the fast rising initial phase, and these differences decrease rapidly with increasing time (Fig. 8a). In contrast, with a low diffusion coefficient, differences between the four samples occur from the slow rising initial phase to long measurement times and these differences decrease slowly with increasing time (Fig. 8b). Both cases differ from the measured desorption kinetics (Fig. 7b), which is characterised by a rapid rising initial phase followed by a slowly rising later phase. Hence, it seems as if processes within the cell wall have a larger impact on the sorption kinetics in the high range of $\mathrm{RH}$. These results are supported by other investigations in the literature, where the deviation of the measured sorption kinetics from a 
simple moisture diffusion process was frequently mentioned as a non-Fickian behaviour (Wadsö 1994a; Krabbenhoft and Damkilde 2004; Olek et al. 2005; Himmel and Mai 2016). However, as sample thickness was shown to have a considerable impact on the sorption kinetics, the uptake and release of water cannot solely depend on processes within the cell wall of wood. Hence, either a barrier for the moisture transport or a process that depends on the sample mass but not on the sample orientation (i.e. a dependence on the number of sorption sites) seems to be relevant in the high range of RH. Thermal effects, a boundary layer, or an additional or modified moisture transport might be possible candidates for this process. Future experiments should thus compare the sorption kinetics of chemically modified samples (see e.g. Thybring and Fredriksson 2021 and references therein) or of samples with different dry densities to investigate the impact of sorption sites on the absorption and desorption of water in the high range of $\mathrm{RH}$. It should be mentioned that with increasing sample thickness diffusion processes become more dominant as their characteristic time scales with the square of the thickness $\left(t \sim d^{2}\right)$. As a result, the uptake and release of water in thicker samples should be increasingly dominated by diffusion (e.g. water vapour diffusion through the lumen-pit-ray system). This might explain the increasing differences in the sorption kinetics between samples in and across fibre direction with increasing thickness (see Fig. 7a,b and Fig. S3a,b in the Supplementary Information).

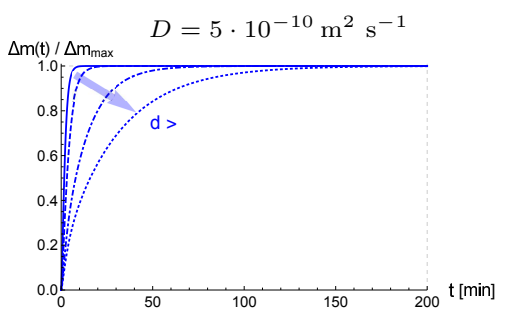

(a)

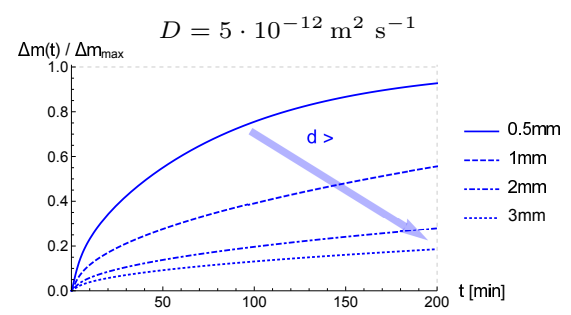

(b)

Fig. 8 Simulated solutions for diffusion in a plane sheet with different sheet thickness for a high (a) and low (b) diffusion coefficient. Arrows indicate the impact of increasing sheet thickness and boundary conditions are chosen corresponding to desorption at high $\mathrm{RH}$

\section{Transition low to high range of $R H$ :}

The sorption kinetics of thin wood samples in and across fibre direction differ significantly between the low and high range of RH. Hence, there seems to be at least one transition in the processes which dominate the uptake and release of water in thin wood samples. To allow such a transition between two or more processes to happen, either the characteristic times of the involved processes or their relative amplitudes (or both) have to change with increasing RH. As the uptake and release of water depends on moisture transport, sorption and sorption related processes, the slowest of the involved pro- 
cesses will dominate the sorption kinetics. This fact has to be considered in all types of experiments under transient conditions in $\mathrm{RH}$ (e.g. measuring the heat of sorption or swelling). To investigate the transition between the low and high range of $\mathrm{RH}$, the ratio between the mass change of the tangential and longitudinal samples $\left(\Delta m_{T} / \Delta m_{L}\right)$ for each sample thickness was used. Evaluation time for the ratio was chosen to $t_{e v}=10$ min to capture particularly the initial phase of the sorption kinetics. If $\Delta m_{T} / \Delta m_{L}<1$, the uptake and release of water for the tangential sample is slower than for the longitudinal sample. In the case of $\Delta m_{T} / \Delta m_{L}=1$, the uptake and release of water is identical for both samples. The fact that a similar initial mass change between the samples ensures a similar sorption kinetics until EC is reached is supported by the measurements of this study (see e.g. Fig. 7). Figure 9 shows the four mass change ratios along the moisture content of wood.

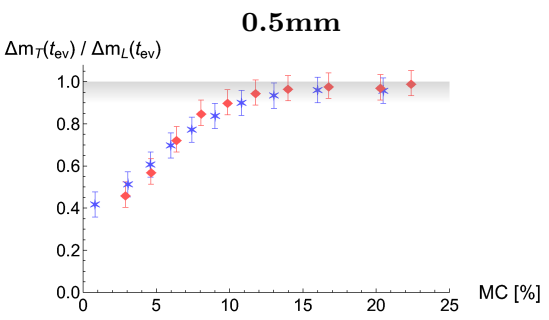

(a)

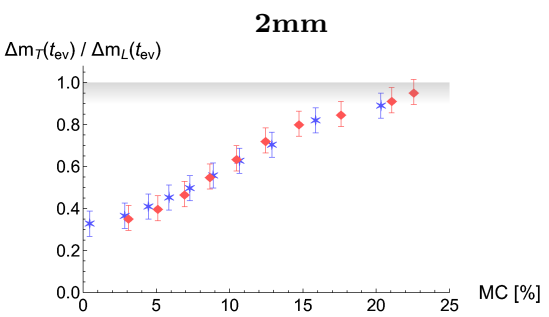

(c)

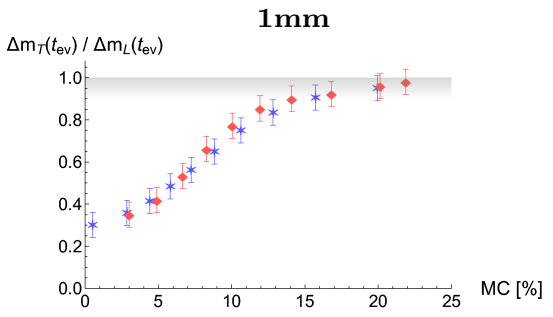

(b)

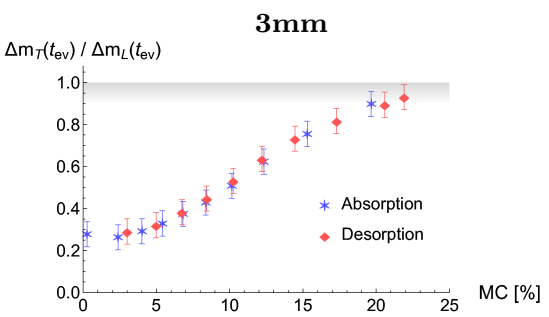

(d)

Fig. 9 Initial mass change ratio between tangential and longitudinal samples during absorption (*) and desorption ( $\bullet$ ) for a sample thickness of $0.5 \mathrm{~mm}(\mathrm{a}), 1 \mathrm{~mm}(\mathrm{~b}), 2 \mathrm{~mm}$ (c), and $3 \mathrm{~mm}(\mathrm{~d})$. Grey area indicates the range with a similar sorption kinetic between the tangential and longitudinal samples

470 For each sample thickness a continuous increase of the ratio $\Delta m_{T} / \Delta m_{L}$ can 471 be seen. These results indicate a continuous transition in the processes which 472 dominate the initial sorption kinetics between the low and high range of $\mathrm{RH}$. 473 Since for each thickness the ratio $\Delta m_{T} / \Delta m_{L}$ between absorption and desorp474 tion is similar, the processes involved in this transition must be independent 475 on the uptake and release of water. Similar results were obtained for the ratio 
between the radial and longitudinal samples (Fig. S4 in the Supplementary Information). Consequently, processes which are different between absorption and desorption seem to have a minor impact on the initial sorption kinetics. Further, moisture content of wood seems to be an appropriate parameter for the transition as in a representation over $\mathrm{RH}$ differences between absorption and desorption were observed. This appears plausible as changes in wood properties (and thus in the involved processes) should depend mainly on the state of the material instead on the surrounding conditions (see e.g. Niemz 1993). Comparing the four mass change ratios among each other, an increase of the ratio with decreasing sample thickness can be seen. This seems reasonable, as in the limiting case of a sample thickness close to the cell wall thickness water vapour diffusion through the lumen-pit-ray system can be omitted and should lead to a similar sorption kinetics between the anatomical orientations. In contrast, with increasing sample thickness water vapour diffusion through the lumen-pit-ray system will get more dominant since the characteristic time for a diffusion process increases proportionally to the square of the sample thickness. An evaluation of the mass change ratio at a later time led also to an increase of $\Delta m_{T} / \Delta m_{L}$. This supports the findings that water vapour diffusion across fibre direction has a considerable impact on the measured sorption kinetics even after the initial phase. It should be mentioned that along with a later evaluation time differences between the mass change ratio during absorption and desorption emerged. This indicates that processes which are different between absorption and desorption have a larger impact on the sorption kinetics at the later phase.

\subsection{Moisture transport across fibre direction:}

To evaluate if moisture transport properties change with MC, the initial uptake and release of water between the low and high range of $\mathrm{RH}$ was compared. Absorption at low $\mathrm{RH}$ and desorption at high $\mathrm{RH}$ were used to avoid the ranges with a slow change of $\mathrm{RH}$ of the sorption device (see Section 2.3). As shown in Table 2, the initial mass change $\left(t_{e v}=10 \mathrm{~min}\right)$ for the thinnest sample in longitudinal direction is smaller at high RH compared to low RH. A similar behaviour was observed for the thicker samples (cf. Fig. 3c,d). Hence, either the moisture transport decreases noticeable with increasing $\mathrm{MC}^{2}$, or sorption and sorption related processes have to increase in characteristic time and/or in relative amplitude. In contrast to the samples in fibre direction, samples across fibre direction were shown to have a larger initial mass change at high $\mathrm{RH}$ compared to low RH (see Table 2). Again, a similar behaviour was observed for the thicker samples (cf. Fig. 4c,d and Fig. S1c,d in the Supplementary Information). Based on the fact that at low MC water vapour diffusion across

2 The small decrease of the water vapour diffusion coefficient in air (Schirmer 1938; VDIGesellschaft 2006) is too low to explain these differences between the low and high range of RH. Even the often mentioned increasing bound water diffusion inside the cell wall cannot resolve this issue, since it would rather force the opposite trend. 
Table 2 Initial uptake (at low $\mathrm{RH}$ ) and release of water (at high $\mathrm{RH}$ ) standardised to minimum sample mass for samples with a thickness of $0.5 \mathrm{~mm}$ in the longitudinal $(\mathrm{L})$, tangential $(\mathrm{T})$ and radial $(\mathrm{R})$ direction. Measurement error is below $\pm 0.06 \%$

\begin{tabular}{cccc}
\hline Sample & Low RH [\%] & High RH [\%] & Difference [\%] \\
\hline L & 1.96 & 1.54 & $\mathbf{- 0 . 4 2}$ \\
T & 0.82 & 1.50 & $\mathbf{+ 0 . 6 8}$ \\
R & 0.92 & 1.55 & $+\mathbf{0 . 6 3}$ \\
\hline
\end{tabular}

515 fibre direction has a larger impact on the sorption kinetics than in fibre di$\mathbf{5 1 6}$ rection, these results indicate that moisture transport across fibre direction $\mathbf{5 1 7}$ has to increase with increasing MC. Alternatively, one of the barriers which 518 prevents the uptake and release of water across fibre direction has to decrease 519 considerably with increasing MC. This view is supported by other investiga$\mathbf{5 2 0}$ tions in the literature, where an increase of moisture transport across fibre 521 direction was frequently mentioned (Siau 1984; Droin-Josserand et al. 1989; 522 Krabbenhoft and Damkilde 2004). Furthermore, steady-state diffusion measurements on pine, spruce and beech samples (see Wadsö 1994b; Sonderegger et al. 2011 and references therein) as well as gas permeability measurements on several hardwoods (Choong et al. 1974) also reported about an increase of moisture transport across fibre direction with increasing MC. Sorption and sorption related processes by contrast seem to be less responsible for this significant increase, as they should have a similar impact for the three anatomical orientations. To analyse if such a significant increase of moisture transport across fibre direction can be explained with the existing concepts of a water vapour transport through the lumen-pit-ray system or a bound water transport through the cell wall of wood (see e.g. Engelund et al. 2012 and references therein), a short discussion on the two transport mechanism is given below. The coupled moisture transport will not be discussed, as a proper treatment with a coupled transport model needs an accurate information on both sorption and sorption related processes, which are still not available. Further, for a meaningful simulation a three dimensional modelling using the accurate three dimensional wood structure (e.g. using X-ray tomographic microscopy (Trtik et al. 2007)) is essential, as a one dimensional simulation cannot sufficiently capture the complex movement of moisture and the associated interaction between moisture transport, sorption and sorption related processes inside the wood samples.

Transport of water vapour:

545 The moisture transport through the lumen-pit-ray system of wood is usually 546 described by a water vapour diffusion process. For this, the water vapour dif$\mathbf{5 4 7}$ fusion coefficient in air (see e.g. Schirmer 1938) is commonly used by applying 548 a constant reduction factor for the various pathways along the three anatom549 ical orientations (cf. Section 2.4). According to the geometrical differences, 
the diffusion coefficient in longitudinal direction is given to be considerable larger than in tangential (or radial) direction, $D_{w v}^{L} \approx 20 \cdot D_{w v}^{T}$ (Krabbenhoft and Damkilde 2004; Frandsen et al. 2007; Eitelberger et al. 2011). An evaluation of the water vapour diffusion coefficient in air between $0 \% \mathrm{RH}$ and $90 \% \mathrm{RH}$ yields a decreases of less than $3 \%$. This slight decrease in combination with the constant reduction coefficients can neither explain the increased moisture transport across fibre direction nor the similar sorption kinetics for samples with the same thickness in the high range of RH. Similar results can be obtained when the transport of water vapour includes an instantaneous absorption and desorption of water vapour on the surface of the cell wall (see Section 2.4). This is because the effective diffusion coefficients along the three anatomical orientations are similarly reduced by the uptake and release of water. Thus, to describe an increase of moisture transport across fibre direction with the diffusion of water vapour through the lumen-pit-ray system, the tangential and radial water vapour diffusion coefficients must increase with MC. A possible mechanism for this increase might be a higher permeability of the bordered pit pairs, either by an increased permeability of the pit membrane (torus or margo) or by a movement of the pit membrane to open the pit (i.e. deaspiration of pits). This seems reasonable, since the resistance of pits to the diffusion of non-swelling gases across fibre direction was mentioned e.g. to be more than 99\% for dry conifer wood (Petty 1973). The impact of pit aspiration on the gas permeability in wood is given in literature (Comstock 1970; Smith and Banks 1971; Meyer 1971), although changes of pit aspiration where only mentioned to be caused by the adhesion force of a liquid with a certain surface tension (Liese and Bauch 1967; Comstock and Côté 1968; Drive and Aberdeen 1972; Flynn 1995). Consequently, experimental studies are necessary to investigate if the position of the pit membrane or its permeability can change with increasing $\mathrm{MC}$ of wood. Alternatively, water vapour sorption experiments on wood samples with a different pit structure might be compared to estimate the impact of pit permeability on the increased uptake and release of water across fibre direction. In comparison to Norway spruce (Picea abies), northern white cedar (Thuja occidentalis) would be of interest, as the pit membrane hardly shows a thickened torus and the pits seem to remain more permeable at low MC (Liese and Bauch 1967; Bauch et al. 1972).

\section{Transport of bound water:}

Inside the cell wall of wood, moisture transport is usually described by a diffusion process, in which water is transported through the cell wall in a bound state (see e.g. Krabbenhoft and Damkilde 2004 and references therein). Bound water diffusion coefficients were given to increase exponentially with $\mathrm{MC}$ and the coefficient in longitudinal direction is assumed to be larger than in tangential (or radial) direction, $D_{b w}^{L}(M C) \approx 2.5 \cdot D_{b w}^{T}(M C)$ (Siau 1984). An evaluation of this bound water diffusion coefficients at $0 \%$ and $20 \% \mathrm{MC}$ (i.e. at $0 \%$ and approximately $90 \% \mathrm{RH}$ ) gives an increase of one order of magnitude for each direction. With such an increase of the diffusion coefficients it is 
difficult to justify both the similar sorption kinetics between samples of different anatomical orientation and the differences in the sorption kinetics between samples of different thickness (see Fig. 7 and Fig. S3 in the Supplementary Information). Though, it should be mentioned that these bound water diffusion coefficients are not necessarily correct (see e.g. Wadsö 1993b and references therein) and that the difference in the bound water diffusion coefficients has never been directly determined. However, there seems to be two major problems if bound water diffusion is used to explain the increasing uptake and release of water for samples across fibre direction. Firstly, water vapour has to be bound on the surface of the cell wall prior a transport of bound water through the cell wall is possible. Sorption and sorption related processes are thus involved and need to be fast enough to allow an additional transport path across or an alternative transport path along the cell wall of wood. As a consequence of the fast processes within the cell wall, the sorption kinetics of thin wood samples should increasingly resemble a diffusion process in the high range of $\mathrm{RH}$, which contradicts the measured results and the results in literature (Avramidis and Siau 1987; Wadsö 1993a; Frandsen et al. 2007). Secondly, to provide a similar moisture transport in and across fibre direction, the combined water vapour and bound water transport has to be comparable for the corresponding anatomical orientations. As water vapour diffusion across fibre direction is considerably less than in fibre direction, the corresponding bound water diffusion coefficient has to be in a similar magnitude as the water vapour diffusion coefficient to resolve this issue. However, such high values seem to be unrealistic compared to bound water diffusion coefficients in other materials (Aldous et al. 1997; Aguerre and Suarez 2004; Wang et al. 2020). Consequently, an alternative transport mechanism should be found in which $\mathrm{H}_{2} \mathrm{O}$-molecules are transported through the cell wall without immediate binding to the wood polymers. One possibility could be a transport of water vapour or water clusters through the cell wall, where the $\mathrm{H}_{2} \mathrm{O}$-molecules interact mainly with the bound water molecules instead of with the wood polymers. Such a change in the binding behaviour of the $\mathrm{H}_{2} \mathrm{O}$-molecules could then possibly be associated with the strong increase in the sorption isotherms.

\section{Conclusion}

Water vapour sorption experiments on thin Norway spruce samples have shown that at low moisture content of wood, the initial uptake and release of water is influenced by the diffusion of water vapour through the lumen-pit-ray system. Differences in the initial sorption kinetics can thus be observed between samples with a different thickness and between samples with a different anatomical orientation (i.e. in and across fibre direction). With increasing moisture content, the results indicated an increased moisture transport across fibre direction and an increased impact of cell wall processes on the uptake and release of water. These changes might explain the similar sorption kinetics between thin samples in and across fibre direction in the high range of relative humid- 
ity. However, sample thickness was shown to have a considerable impact on the uptake and release of water. Therefore, an additional or modified process must be considered at an increased moisture content of wood, which mainly depends on the sample thickness (or on the number of sorption sites) but not on the anatomical orientation. Water vapour sorption experiments with chemically modified wood or with wood of different dry density should provide further information on this process. Nevertheless, additional measurements on the sorption related processes (e.g. measuring the heat of sorption) might be necessary to correctly interpret the water vapour sorption behaviour at an increased moisture content of wood. Longitudinal samples with a thickness of less than $1 \mathrm{~mm}$ should be used for these measurements and the samples should be directly exposed to the water vapour-air flow. Regarding the interpretation and modelling of sorption data and other experimental investigations under transient conditions in relative humidity, the transport of moisture and the impact of sample thickness have to be considered particularly at an increased moisture content of wood.

Acknowledgements This work was partly funded by the Tiroler Wissenschaftsförderung (Gefördert aus Mitteln des Landes Tirol) under the grand number GZ: F.16963/5-2019. Their financial support is gratefully acknowledged. Roman Lackner is acknowledged for providing the sorption device (Unit of Material Technology, Universität Innsbruck) and Thomas Bechtold is acknowledged for reading the final version of the manuscript (Research Institute of textile chemistry and textile physics, Universität Innsbruck).

Competing interests The author has no relevant financial or non-financial interests to declare.

\section{References}

Aguerre RJ, Suarez C (2004) Diffusion of bound water in starchy materials: Application to drying. J Food Eng 64(3):389-395, DOI 10.1016/j.jfoodeng.2003.11.007

Aldous BJ, Franks F, Greer AL (1997) Diffusion of water within an amorphous carbohydrate. J Mater Sci 32(2):301-308, DOI 10.1023/A:1018584812561

Avramidis S, Siau JF (1987) An investigation of the external and internal resistance to moisture diffusion in wood. Wood Sci Technol 21(3):249-256, DOI 10.1007/BF00351396

Bauch J, Liese W, Schultze R (1972) The morphological variability of the bordered pit membranes in gymnosperms. Wood Sci Technol 6(3):165-184, DOI 10.1007/BF00351575

Choong E, Tesoro F, Manwiller F (1974) Permeability of twenty-two small diameter hardwoods growing on southern pine sites. Wood Fiber Sci 6(1):91101

Christensen G, Hergt H (1969) Effect of Previous History on Kinetics of Sorption By Wood Cell Wall. J Polym Sci Chem 7(8 Pt A-1):2427-2430 
Christensen GN (1960) Kinetics of sorption of water vapour by wood. 1. The effect of sample thickness. Aust J Appl Sci 11(2):295-304

Christensen GN, Kelsey KE (1959) Die Geschwindigkeit der Wasserdampfsorption durch Holz [The rate of Sorption of Water Vapour by Wood]. Eur J Wood Wood Prod 17(5):178-188

Comstock GL (1970) Directional permeability of softwoods. Wood Fiber 1(4):283-289

Comstock GL, Côté WA (1968) Factors affecting permeability and pit aspiration in coniferous sapwood. Wood Sci Technol 2(4):279-291, DOI 10.1007/BF00350274

Crank J (1975) The Mathematics of Diffusion, 2nd edn. Oxford University Press

Drive M, Aberdeen O (1972) The aspiration of bordered pits in conifer wood. Proc R Soc London Ser B Biol Sci 181(1065):395-406, DOI 10.1098/rspb.1972.0057

Droin-Josserand A, Taverdet JL, Vergnaud JM (1989) Modelling the process of moisture absorption in three dimensions by wood samples of various shapes: cubic, parallelepipedic. Wood Sci Technol 23(3):259-271, DOI 10.1007/BF00367739

Eitelberger J, Svensson S (2012) The Sorption Behavior of Wood Studied by Means of an Improved Cup Method. Transp Porous Media 92(2):321-335, DOI 10.1007/s11242-011-9905-8

Eitelberger J, Hofstetter K, Dvinskikh SV (2011) A multi-scale approach for simulation of transient moisture transport processes in wood below the fiber saturation point. Compos Sci Technol 71(15):1727-1738, DOI 10.1016/j.compscitech.2011.08.004

Engelund ET, Thygesen LG, Svensson S, Hill CAS (2012) A critical discussion of the physics of wood-water interactions. Wood Sci Technol 47(1):141-161, DOI 10.1007/s00226-012-0514-7

Florisson S, Vessby J, Mmari W, Ormarsson S (2020) Three-dimensional orthotropic nonlinear transient moisture simulation for wood: analysis on the effect of scanning curves and nonlinearity. Wood Sci Technol 54(5):11971222, DOI 10.1007/s00226-020-01210-4

Flynn KA (1995) A review of the permeability, fluid flow, and anatomy of spruce (Picea spp.). Wood fiber Sci 27(3):278-284

Frandsen HL, Damkilde L, Svensson S (2007) A revised multi-Fickian moisture transport model to describe non-Fickian effects in wood. Holzforschung 61(5):563-572

Glass SV, Boardman CR, Zelinka SL (2017) Short hold times in dynamic vapor sorption measurements mischaracterize the equilibrium moisture content of wood. Wood Sci Technol 51(2):243-260, DOI 10.1007/s00226-016-0883-4

Hill CAS, Norton A, Newman G (2010) Analysis of the water vapour sorption behaviour of Sitka spruce based on the parallel exponential kinetics model. Holzforschung 64:469-473, DOI 10.1515/HF.2010.059

Himmel S, Mai C (2015) Effects of acetylation and formalization on the dynamic water vapor sorption behavior of wood. Holzforschung 69(5):633-643, 
DOI 10.1515/hf-2014-0161

Himmel S, Mai C (2016) Water vapor sorption of wood modified by acetylation and formalization - Analyzed by a sorption kinetics model and according to modeless thermodynamic considerations. Holzforschung 70(3):203-213, DOI 10.1515/hf-2015-0015

Hozjan T, Svensson S (2011) Theoretical analysis of moisture transport in wood as an open porous hygroscopic material. Holzforschung 65:97-102, DOI 10.1515/HF.2010.122

Jakieła S, Bratasz, Kozłowski R (2008) Numerical modelling of moisture movement and related stress field in lime wood subjected to changing climate conditions. Wood Sci Technol 42(1):21-37, DOI 10.1007/s00226-007-0138-5

Kang W, Kang CW, Chung WY, Eom CD, Yeo H (2008) The effect of openings on combined bound water and water vapor diffusion in wood. J Wood Sci 54(5):343-348, DOI 10.1007/s10086-008-0965-5

Konopka D, Kaliske M (2018) Transient multi-FICKian hygromechanical analysis of wood. Comput Struct 197:12-27, DOI 10.1016/j.compstruc.2017.11.012

Krabbenhoft K, Damkilde L (2004) A model for non-Fickian moisture transfer in wood. Mater Struct Constr 37(273):615-622, DOI 10.1617/14036

Liese W, Bauch J (1967) On the Closure of Bordered Pits in Conifers Zusammenfassung. Wood Sci Technol 1(1):1-13

Meyer RW (1971) Influence of pit aspiration on earlywood permeability of Douglas-Fir. Wood Fiber Sci 2(4):328-339

Murr A (2019) The Relevance of Water Vapour Transport for Water Vapour Sorption Experiments on Small Wooden Samples. Transp Porous Media 128(2):385-404, DOI 10.1007/s11242-019-01253-7

Murr A, Lackner R (2018) Analysis on the influence of grain size and grain layer thickness on the sorption kinetics of grained wood at low relative humidity with the use of water vapour sorption experiments. Wood Sci Technol 52(3):753-776, DOI 10.1007/s00226-018-1003-4

Niemz P (1993) Physik des Holzes und der Holzwerkstoffe. DRW-Verlag

Nopens M, Riegler M, Hansmann C, Krause A (2019) Simultaneous change of wood mass and dimension caused by moisture dynamics. Sci Rep 9(1):1-11, DOI 10.1038/s41598-019-46381-8

Olek W, Perré P, Weres J (2005) Inverse analysis of the transient bound water diffusion in wood. Holzforschung 59(1):38-45, DOI 10.1515/HF.2005.007

Olek W, Perré P, Weres J (2011) Implementation of a relaxation equilibrium term in the convective boundary condition for a better representation of the transient bound water diffusion in wood. Wood Sci Technol 45(4):677-691, DOI 10.1007/s00226-010-0399-2

Petty JA (1973) Diffusion of non-swelling gases through dry conifer wood. Wood Sci Technol 7(4):297-307, DOI 10.1007/BF00351075

Popescu CM, Hill CA (2013) The water vapour adsorption-desorption behaviour of naturally aged Tilia cordata Mill. wood. Polym Degrad Stab 98(9):1804-1813, DOI 10.1016/j.polymdegradstab.2013.05.021 
Rosen HN (1978) The Influence of External Resistance on Moisture Adsorption Rates in Wood. Wood Fiber Sci 10(3):218-228

Schirmer R (1938) Die Diffusionszahl von Wasserdampf-Luftgemischen und die Verdampfungsgeschwindigkeit. Zeitschrift des Vereins Dtsch Ingenieure (VDI Beiheft) 6(70):170-177

Siau JF (1984) Tranport Processes in Wood. Springer-Verlag Berlin Heidelberg Smith D, Banks W (1971) The mechanism of flow of gases through coniferous wood. Proc R Soc London Ser B Biol Sci 177(1047):197-223, DOI 10.1098/rspb.1971.0023

Sonderegger W, Vecellio M, Zwicker P, Niemz P (2011) Combined bound water and water vapour diffusion of Norway spruce and European beech in and between the principal anatomical directions. Holzforschung 65(6):819-828, DOI 10.1515/HF.2011.091

Thybring EE, Fredriksson M (2021) Wood modification as a tool to understand moisture in wood. Forests 12(3):1-18, DOI 10.3390/f12030372

Thybring EE, Glass SV, Zelinka SL (2019) Kinetics of water vapor sorption in wood cell walls: State of the art and research needs. Forests 10(8), DOI 10.3390/f10080704

Time B (1998) Hygroscopic Moisture Transport in Wood. Phd thesis, Norwegian University of Science and Technology

Trtik P, Dual J, Keunecke D, Mannes D, Niemz P, Stähli P, Kaestner A, Groso A, Stampanoni M (2007) 3D imaging of microstructure of spruce wood. J Struct Biol 159(1):46-55, DOI 10.1016/j.jsb.2007.02.003

VDI-Gesellschaft (ed) (2006) VDI-Wärmeatlas, 10th edn. Springer-Verlag Berlin Heidelberg

Wadsö L (1993a) Measurements of water vapour sorption in wood. Wood Sci Technol 28(1):59-65, DOI 10.1007/BF00193877

Wadsö L (1993b) Studies of Water Vapor Transport and Sorption in Wood. $\mathrm{PhD}$ thesis, Lund University

Wadsö L (1994a) Describing non-Fickian water-vapour sorption in wood. J Mater Sci 29(9):2367-2372, DOI 10.1007/BF00363428

Wadsö L (1994b) Unsteady-state water vapor adsorption in wood: an experimental study. Wood fiber Sci 26(1):36-50

Wang Q, Wang T, Lv Z, Cui M, Zhao Z, Cao X, Wei Q (2020) A Comprehensive Review on Water Diffusion in Polymers Focusing on the Polymer. Polymers (Basel) 12(1)

Xie Y, Hill CA, Jalaludin Z, Curling SF, Anandjiwala RD, Norton AJ, Newman G (2011) The dynamic water vapour sorption behaviour of natural fibres and kinetic analysis using the parallel exponential kinetics model. J Mater Sci 46(2):479-489, DOI 10.1007/s10853-010-4935-0 


\section{Supplementary Files}

This is a list of supplementary files associated with this preprint. Click to download.

- Supplementary.pdf 